\title{
Using capillary electrophoresis to study methylation effect on RNA-peptide interaction ${ }^{*}$
}

\author{
Piotr Mucha ${ }^{1 凶}$, Agnieszka Szyk $^{1}$, Piotr Rekowski ${ }^{1}$ and Paul F. Agris ${ }^{2}$ \\ ${ }^{1}$ Department of Chemistry, University of Gdańsk, Gdańsk, Poland; \\ ${ }^{2}$ Department of Molecular and Structural Biochemistry, North Carolina State University, \\ Raleigh, North Carolina 27695, U.S.A.
}

Received: 22 May, 2003; revised: 11 August, 2003; accepted: 02 September, 2003

Key words: capillary electrophoresis, RN-peptide interaction, methylation, methylated nucleosides, arginine methylation

\begin{abstract}
Methylation of RNA and proteins is one of a broad spectrum of post-transcriptional/translational mechanisms of gene expression regulation. Its functional signification is only beginning to be understood. A sensitive capillary electrophoresis mobility shift assay (CEMSA) for qualitative study of the methylation effect on biomolecules interaction is presented. Two RNA-peptide systems were chosen for the study. The first one consists of a 17-nucleotide analogue $(+27-+43)$ of the yeast tRNA $^{\text {Phe }}$ anticodon stem and loop domain (ASL ${ }^{\text {Phe }}$ ) containing three of the five naturally occurring modifications $\left(2^{\prime}\right.$-O-methylcytidine $\left(\mathrm{Cm}_{32}\right), 2^{\prime}$-O-methylguanine $\left(\mathrm{Gm}_{34}\right)$ and 5-methylcytidine $\left.\left(\mathrm{m}^{5} \mathrm{C}_{40}\right)\right)\left(\mathrm{ASL}^{\mathrm{Phe}}-\mathrm{Cm}_{32}, \mathrm{Gm}_{34}, \mathrm{~m}^{5} \mathrm{C}_{40}\right)$ and $\mathrm{a}$ 15-amino-acid peptide (named $\mathrm{t}^{\mathrm{F}}$ 2: Ser ${ }^{1}$-Ile-Ser-Pro-Trp ${ }^{5}$-Gly-Phe-Ser-Gly-Leu ${ }^{10}$-LeuArg-Trp-Ser-Tyr ${ }^{15}$ ) selected from a random phage display library (RPL). A peptide-concentration-dependent formation of an RNA-peptide complex was clearly observable by CEMSA. In the presence of the peptide the capillary electrophoresis (CE) peak for triply methylated ASL ${ }^{\text {Phe }}$ shifted from 18.16 to 20.90 min. Formation of the complex was not observed when an unmethylated version of ASL ${ }^{\text {Phe }}$ was used. The second system studied consisted of the $(+18)-(+44)$ fragment of the trans-activation
\end{abstract}

\footnotetext{
This work was supported by the University of Gdańsk grant no. BW 8000-5-0239-3, by the State Committee for Scientific Research (KBN, Poland) grant No. 1409/T09/2001/21 (to P.M.) and by grant R01-GM-23027-20 from Department of Health and Human Services, National Institutes of Health (to P.F.A.).

${ }^{\square}$ Corresponding author: Dr. Piotr Mucha, Department of Chemistry, University of Gdańsk, J. Sobieskiego 18, 80-952 Gdańsk, Poland; phone: (48 58) 345 0391; fax: (48 58) 341 0357; e-mail: fly@chemik. chem.univ.gda.pl

Abbreviations: aaRS, aminoacyl-tRNA synthetase; ASL, anticodon stem and loop; CE, capillary electrophoresis; CEMSA, capillary electrophoresis mobility shift assay; LPA, linear-polyacrylamide; RPL, random phage display library; SGE, slab gel electrophoresis; TAR, trans-activation response element; Tat, trans-activator of transcription.
} 
response element of human immunodeficiency virus type 1 (TAR RNA HIV-1) and a 9-amino-acid peptide of the trans-activator of transcription protein (Tat HIV-1) Tat(49-57)- $\mathrm{NH}_{2}$ (named Tat1: Arg ${ }^{49}$-Lys-Lys-Arg ${ }^{52}$-Arg-Gln-Arg-Arg- Arg ${ }^{57}{ }_{-N_{2}}$ ). In the presence of Tat(49-57)- $\mathrm{NH}_{2}$ a significant shift of migration time of TAR from $18.66 \mathrm{~min}$ to $20.12 \mathrm{~min}$ was observed. Methylation of a residue $\operatorname{Arg}^{52} \rightarrow \operatorname{Arg}(\mathrm{Me})_{2}$, crucial for TAR binding, strongly disrupted formation of the complex. Only at a high micromolar peptide concentration a poorly shaped, broad peak of the complex was observed. CE was found to be an efficient and sensitive method for the analysis of methylation effects on interaction of biomolecules.

Post-transcriptional and post-translational modifications of RNAs and proteins are not well understood mechanisms of gene expression regulation. In recent years, however, significant progress has been made in the understanding of their structural and physiological roles. RNA-protein interactions are fundamental to numerous biological processes and the importance of post-transcriptional modifications for RNA function is irrefutable (Agris, 1996; Ashraf et al., 1999; Yarian et al., 2000). Presently over 100 RNA modifications are known (Agris, 1996; Helm et al., 1999). However, the physicochemical contributions of modified nucleosides as identity elements for protein recognition are poorly understood.

tRNA is a model molecule widely used to study the role of modified nucleosides for RNA structure and function. Most modifications known have been found in tRNA (Agris, 1996; Yarian et al., 2000). Methylation is the simplest modification known. Both nucleobase and the sugar moiety of a nucleoside may be methylated (Agris, 1996). Modified nucleosides of tRNA anticodon domain are known to be identity elements for the recognition of cognate tRNA by some aminoacyl-tRNA synthetases (aaRS). A single methyl group of 1-methylguanosine $37\left(\mathrm{~m}^{1} \mathrm{G}_{37}\right)$ prevents misarginylation of $\mathrm{tRNA}^{\mathrm{Asp}}$ by yeast ArgRS and the presence of the modified nucleoside lysidine within the anticodon of Escherichia coli

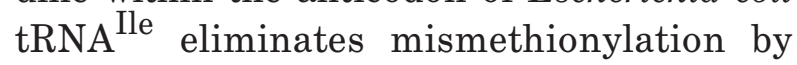
MetRS (Putz et al., 1994; Muramatsu et al., 1988). The recognition and discrimination of the tRNA anticodon domain seem to depend on relatively small regions of aaRS. A peptide of 10 amino acids in length is sufficient to ex- hibit an aaRS specificity (Auld \& Schimel, 1995).

Post-translational modifications are complex events that change the properties of a protein by proteolytic cleavage or by addition of modifying groups to amino-acid residues. Analysis of their role presents formidable challenge. Cellular functions of proteins are often correlated with amino-acid modifications. The best known example is the phosphorylation-dependent regulation of enzymatic activity (Karn, 1999). The mechanism and functions of protein methylation are far less understood. Proteins are methylated on carboxyl groups or on the side-chain nitrogen atoms of lysine, histidine and arginine residues (Aletta et al., 1998). Arginine seems to be especially predestinated to interact with nucleic acids (Gary \& Clarke, 1998). Its guanidinium group potentially forms five hydrogen bonds and its positive charge may be used for positional contacts with the negatively charged phosphate residues of RNA backbone. Methylation does not change the overall positive charge but disturbs the hydrogen bonds pattern created by unmodified arginine guanidinium group and modulates the hydrophobic properties of the side chain. Methylated arginine residues have been found in many RNA-binding proteins (Gary \& Clarke, 1998; Lischwe et al., 1982). Hypothesized roles of arginine methylation include signal transduction, nuclear transport and modulation of nucleic acid activity, particularly RNA (Gary \& Clarke, 1998; Aletta et al., 1998).

Capillary electrophoresis (CE) has become one of the most powerful analytical tech- 
niques used for characterization of biomolecules (Heegaard \& Kennedy, 1999; Yeung, 1999; Todorov \& Morris, 2002). Methylated-(nucleoside or amino acid)-dependent RNA-protein interaction is difficult to study because of the inherent problems in homogenous isolation and characterization of functional RNA and protein molecules. We thus opted for solid phase synthesis of both RNA and peptide using methylated amino acids or nucleosides as building blocks. Through this approach precise control of modification incorporation may be achieved. Small methylated biomolecules, such as amino acids or nucleotides have been studied by CE previously (Causse et al., 2000; Liebich et al., 1998). In this paper a capillary electrophoresis mobility shift assay (CEMSA) to study methylation influenced RNA-peptide interaction is presented. Two examples of methylation-influenced RNA-peptide interaction were studied. Peptide $\mathrm{t}^{\mathrm{F}} 2$, the most populated ligand from a random 15-amino acid long phage display library (RPL) specifically binds triply modified anticodon domain of yeast tRNA ${ }^{\mathrm{Phe}}$, $\mathrm{ASL}^{\text {Phe }}-\mathrm{Cm}_{32}, \mathrm{Gm}_{34}, \mathrm{~m}^{5} \mathrm{C}_{40}$ in a methylation-dependent manner (Mucha et al., 2001). These methylated nucleosides naturally occur in the anticodon domain of yest tRNA ${ }^{\text {Phe }}$ (Fig. 1). To study the effect of protein methylation on RNA-protein interaction, the TAR-Tat HIV-1 system was chosen. Interaction of TAR $(+18-+44)$ with an arginine rich region Tat(49-57) is mediated by the single arginine residue $\mathrm{Arg}^{52}$ (Calnan et al., 1991). This residue forms a specific network of hydrogen bonds with the bulge region of TAR. One can conclude that distortion of the guanidinium group structure of $\mathrm{Arg}^{52}$ by methylation should modify the hydrogen bond net and decrease Tat peptide affinity for TAR. Using CEMSA a positive and negative influence of methylation on RNA-peptide interaction were easily observed.

\section{MATERIALS AND METHODS}

RNA synthesis. Unmodified and triply modified 17-nucleotide stem-loop of anticodon domain $(+27-+43)$ of yeast tRNA ${ }^{\text {Phe }}\left(\mathrm{ASL}^{\mathrm{Phe}}\right)$ were synthesized using standard RNA phosphoramidite method as described previously (Mucha et al., 2001). The 27-nucleotide hairpin-bulge $(+18-+44)$ TAR HIV-1 was purchased from Commonwealth Biotechnologies Inc. (U.S.A). Structures of the RNAs are shown in Fig 1.

Peptide synthesis. Peptides $\mathrm{t}^{\mathrm{F}} 2$, Tat(49-57)- $\mathrm{NH}_{2}$ (named Tat1) and its methylated analogue $\mathrm{Arg}^{52} \rightarrow \operatorname{Arg}(\mathrm{Me})_{2}$ (named Tat5) were synthesized by the solid phase method using Fmoc/TBTU protocol as described previously (Mucha et al., 2002). The peptide sequences are shown in Fig. 1.
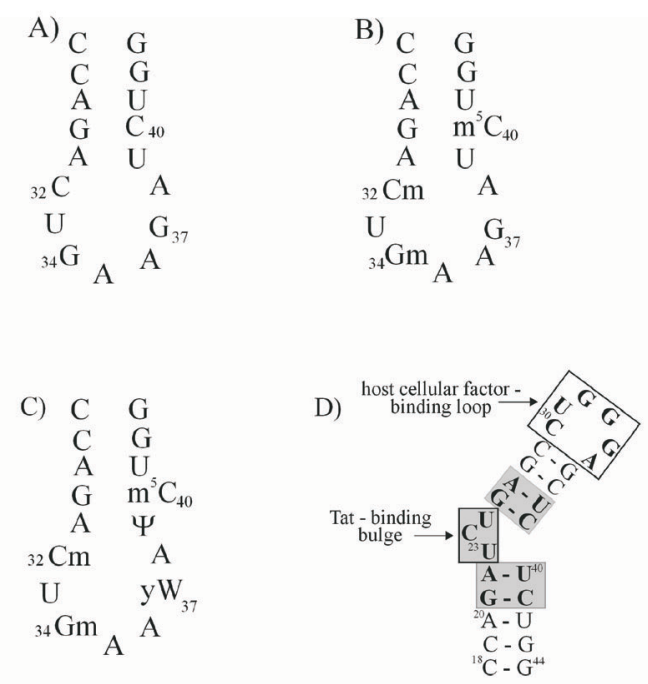

t $^{\mathrm{F}} 2$ Ser $^{1}$-Ile-Ser-Pro-Trp ${ }^{5}$-Gly-Phe-Ser-Gly-Leu ${ }^{10}$-Leu-Arg-Trp-Ser-Tyr ${ }^{15}$

Tat1 $\quad$ Arg $^{49}$-Lys-Lys-Arg ${ }^{52}$-Arg-Gln-Arg-Arg-Arg ${ }^{57}-\mathrm{NH}_{2}$

Tat5 Arg $^{49}$-Lys-Lys-Arg(Me) ${ }_{2}{ }^{52}$-Arg-Gln-Arg-Arg-Arg ${ }^{57}-\mathrm{NH}_{2}$

Figure 1. Secondary structure of unmethylated ASL $^{\text {Phe }}$ (A), triply methylated ASL ${ }^{\text {Phe }}$ (B), native yeast tRNA $^{\text {Phe }}$ anticodon domain (C) and fragment of TAR studied (D).

Nucleotides important for Tat binding are bolded and shadowed. Sequences of peptides are shown at the bottom. $\operatorname{Arg}^{52}$ of Tat critical for TAR binding is bolded. 
RNA-peptide complex preparation. To investigate RNA-peptide binding different concentrations (2.1-210 $\mu \mathrm{M})$ of Tat peptides and $2.1-63 \mu \mathrm{M}$ of peptide $\mathrm{t}^{\mathrm{F}} 2$ were tested. An RNA-peptide complex was formed by mixing pre-formed RNA (heated to $80^{\circ} \mathrm{C}$ for $3 \mathrm{~min}$ and then cooled slowly to room temperature) with a peptide in binding buffer $-10 \mathrm{mM}$ Tris $/ \mathrm{HCl}$, $70 \mathrm{mM} \mathrm{NaCl}, 20 \mathrm{mM}$ EDTA, 5\% glycerol, $\mathrm{pH}$ 7.5. The complex was incubated for $30 \mathrm{~min}$ at $0^{\circ} \mathrm{C}$ before CEMSA analysis. Final RNA concentration was $2.1 \mu \mathrm{M}$. All solutions were prepared using Milli Q water (Millipore).

Capillary mobility shift assay (CEMSA). CEMSA experiments were performed on a Beckman P/ACE 2100 capillary electrophoresis system using a BioCap LPA coated capillary (BioRad) $75 \mu \mathrm{m} \times 57 \mathrm{~cm}$ (50 cm to the detector), running buffer: $267 \mathrm{mM}$ Tris/borate with polymer modifier (BioRad), the inherent $\mathrm{pH}$ of the commercial running buffer $(\mathrm{pH}$ 8.3) was modified to $\mathrm{pH} 7.0$ using solid boric acid. Reverse polarity, constant voltage $-15 \mathrm{kV}$, temp. $20.1^{\circ} \mathrm{C}$, electrokinetic injection for $20 \mathrm{~s}$ at $10 \mathrm{kV}$ and detection at $254 \mathrm{~nm}$ were applied. The capillary was pre-treated with water for $20 \mathrm{~min}$, with the washing buffer (BioRad) for $5 \mathrm{~min}$, with water for $5 \mathrm{~min}$ and finally with the running buffer for 5 min before use. The capillary was washed between runs with the running buffer for $3 \mathrm{~min}$. All solutions were filtered through a $0.22 \mu \mathrm{m}$ teflon membrane prior to use.

\section{RESULTS}

\section{CEMSA of ASL ${ }^{\text {Phe }}$ with peptide $t^{F_{2}}$ binding}

Methylation-dependent RNA-protein interaction is a complex, not fully understood phenomenon. Because of the unique features of $\mathrm{CE}$, such as high separation efficiency, short analysis time and minute amounts of samples, this technique should be useful to study methylation-dependent interactions of biomolecules. To achieve good resolution of free and complexed RNA and to avoid adsorption of the molecules to the internal capillary wall, linear polyacrylamide (LPA)-coated capillary and sieving matrix containing separation buffer were used. A triply modified yeast tRNA $^{\text {Phe }}$ anticodon stem and loop domain (ASL ${ }^{\mathrm{Phe}}$ ), $\mathrm{Cm}_{32}, \mathrm{Gm}_{34}$ and $\mathrm{m}^{5} \mathrm{C}_{40}$, was employed to select tRNA-binding peptides from an RPL (Fig. 1). Peptide $\mathrm{t}^{\mathrm{F}} 2$ with the highest affinity for the triply modified ASL ${ }^{\text {Phe }}$ was selected from the RPL (Mucha et al., 2001). The binding affinity of the triply modified ASL ${ }^{\text {Phe }}$ for peptide $\mathrm{t}^{\mathrm{F}} 2\left(K_{\mathrm{d}}=1.3 \pm 0.4 \mu \mathrm{M}\right)$ determined by fluorescence quenching of the peptide's tryptophans, was comparable to that of the native yeast $t R N A^{\text {Phe }}$ for peptide $\mathrm{t}^{\mathrm{F}} 2\left(K_{\mathrm{d}}=2.3 \pm\right.$ $0.4 \mu \mathrm{M}$ ) (Mucha et al., 2001). Although we were able to characterize the peptide's affinity and specificity for variously modified ASL ${ }^{\text {Phe }}$ using fluorescence spectroscopy, attempts to study these interactions by standard slab gel electrophoresis (SGE) were unsuccessful. These interactions were easily observable using CEMSA. Triply modified ASL ${ }^{\text {Phe }}$ was visible as a single peak with migration time of 18.16 min (Fig. 2). The efficiency of complex formation of the triply modified ASL ${ }^{\text {Phe }}$ with peptide $\mathrm{t}^{\mathrm{F}} 2$ was peptide concentration dependent (Fig. 2). In the presence of a constant amount of triply modified ASL ${ }^{\text {Phe }}(2.1 \mu \mathrm{M})$, a new peak of increasing size and a slower migration time (20.90 min) was observed with increasing concentration of the peptide (Fig. 2). At an equimolar $\mathrm{ASL} \mathrm{Phe}^{\mathrm{Ph}} \mathrm{F}_{2}$ concentration of $2.1 \mu \mathrm{M}$ no shift of the RNA peak was observed (not shown). A small peak $\left(t_{\mathrm{m}}=\right.$ $20.90 \mathrm{~min}$ ) of the complex only became visible at higher peptide concentrations (Fig. 2). With increasing concentration of peptide $\mathrm{t}^{\mathrm{F}} 2$ complex formation increased. The migration time of the complex was independent of the peptide concentration and only one peak in addition to the unbound RNA was observed. This result indicates that only one type of RNA-peptide complex was formed. In the presence of the denaturating agent sodium dodecylsulfate the complex dissociated and 


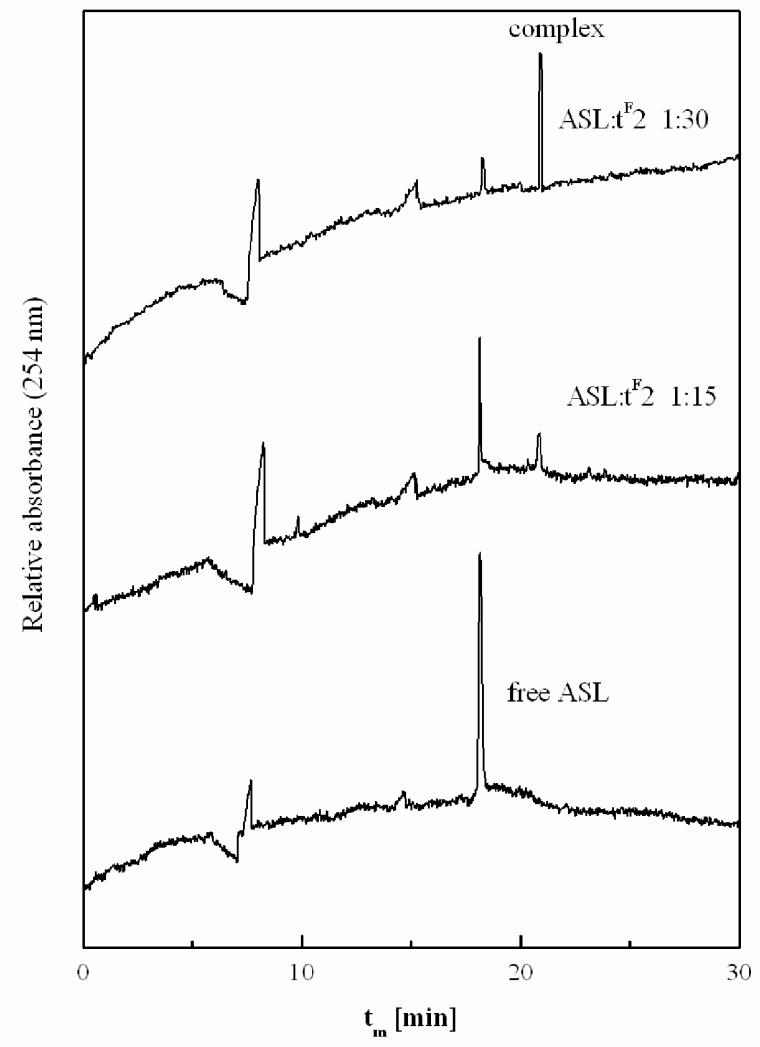

Figure 2. CEMSA of $\mathrm{ASL}^{\mathrm{Phe}}-\mathrm{Cm}_{32}, \mathrm{Gm}_{34}, \mathrm{~m}^{5} \mathrm{C}_{40}$ interactions with peptide $\mathrm{t}^{\mathrm{F}}$.

Free and peptide-bound RNA is observed in the presence of increasing concentration of the peptide. For experimental conditions see Material and Methods. The molar ratio of triply methylated ASL ${ }^{\mathrm{Ph}}$ to $\mathrm{t}^{\mathrm{F}} 2$ peptide is shown for each sample analyzed. Peaks with migration time around $7 \mathrm{~min}$ represent buffer effects.

only free ASL was visible (not shown). Previous observations of complex formation by fluorescence spectroscopy showed that triply modified ASL ${ }^{\text {Phe }}$ bound peptide $t^{\mathrm{F}_{2}}$ at a $1: 1$ stoichiometry (Mucha et al., 2001). Unmodified $\mathrm{ASL}^{\text {Phe }}$ had a significantly reduced affinity for peptide $\mathrm{t}^{\mathrm{F}} 2\left(K_{\mathrm{d}} \approx 70 \mu \mathrm{M}\right)$ as determined by fluorescence quenching (Mucha et al., 2001) and no affinity for this peptide was observed by CEMSA up to a 100 -fold peptide excess (not shown).

\section{CEMSA of TAR-Tat peptide interaction}

TAR-Tat HIV-1 interaction is responsible for efficient elongation of viral mRNAs during transcription of proviral DNA integrated in human chromosome (Karn, 1999). The single residue $\mathrm{Arg}^{52}$ within an arginine rich fragment of Tat is responsible for the binding specificity (Calnan et al., 1991). Thus, methylation of $\mathrm{Arg}^{52}$ should change the hydrogen bonds pattern created by its guanidinium group and modify the binding affinity. Native Tat(49-57)- $\mathrm{NH}_{2}$ fragment was used as a positive control to study the methylation effect on TAR-Tat interaction (Fig. 3). A single peak of TAR with migration time $t_{\mathrm{m}}=18.66 \mathrm{~min}$ was clearly visible at TAR sample concentration of $2.1 \mu \mathrm{M}$ (Fig. 3). Free TAR migrates faster than its complexed form as would be expected given the smaller charge to mass ratio of the complex and the binding was observed as electrophoretic mobility shift of the TAR's peak (Fig. 3). The effect of peptide concentration on

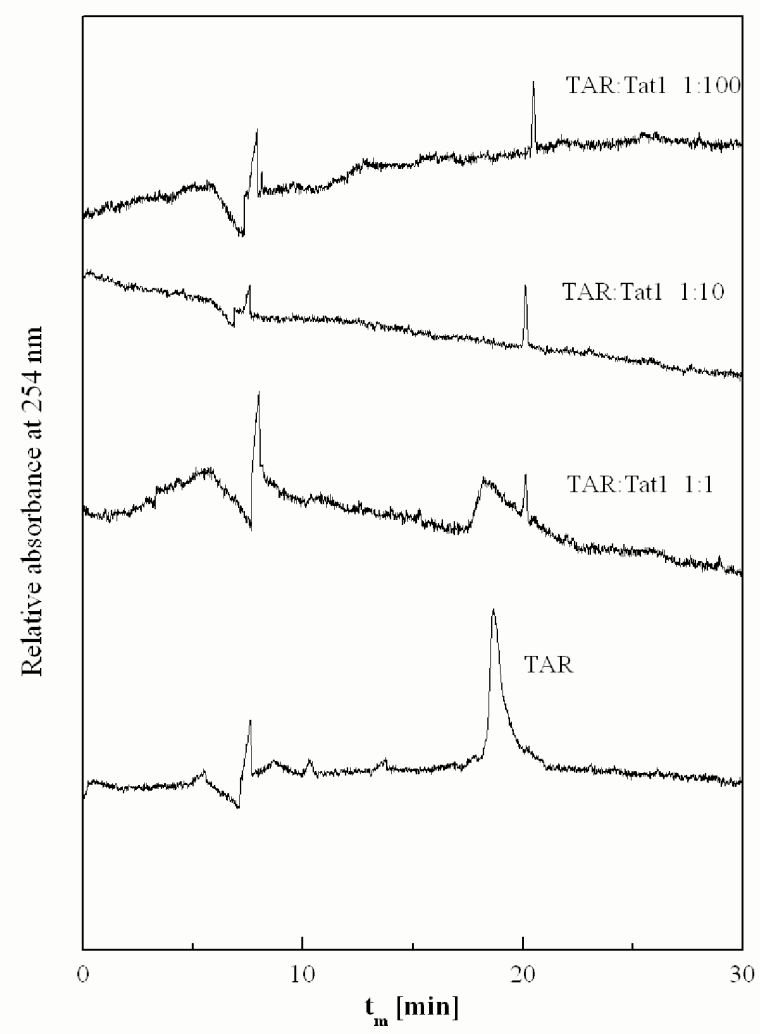

Figure 3. CEMSA of TAR-Tat1 peptide interaction.

The conditions were the same as for Fig. 2. Peaks with migration time around 7 min represent buffer effects. 
the efficiency of RNA-peptide complex formation was evaluated at the peptide concentration range of $2.1-210 \mu \mathrm{M}$, an equivalent of 1-100-fold excess of the peptide over TAR. The peak of unbound TAR dominated at low peptide excess. Increasing peptide concentration promoted the complex formation. At the TAR/peptide molar ratio 1:10 only a peak of the complex $\left(t_{\mathrm{m}}=20.12 \mathrm{~min}\right)$ was observed. Incubation of TAR with different amounts of peptide yields only the single peak of the complex even at high excess (100-fold) of the peptide, indicating that only specific interaction has occurred (Fig. 3). CEMSA experiments showed that methylation of $\mathrm{Arg}^{52}$ of the Tat peptide strongly influenced the TAR-Tat peptide interaction. Methylation $\operatorname{Arg}^{52} \rightarrow \operatorname{Arg}(\mathrm{Me})_{2}$ of Tat5 peptide, where two methyl groups were asymmetrically intro-

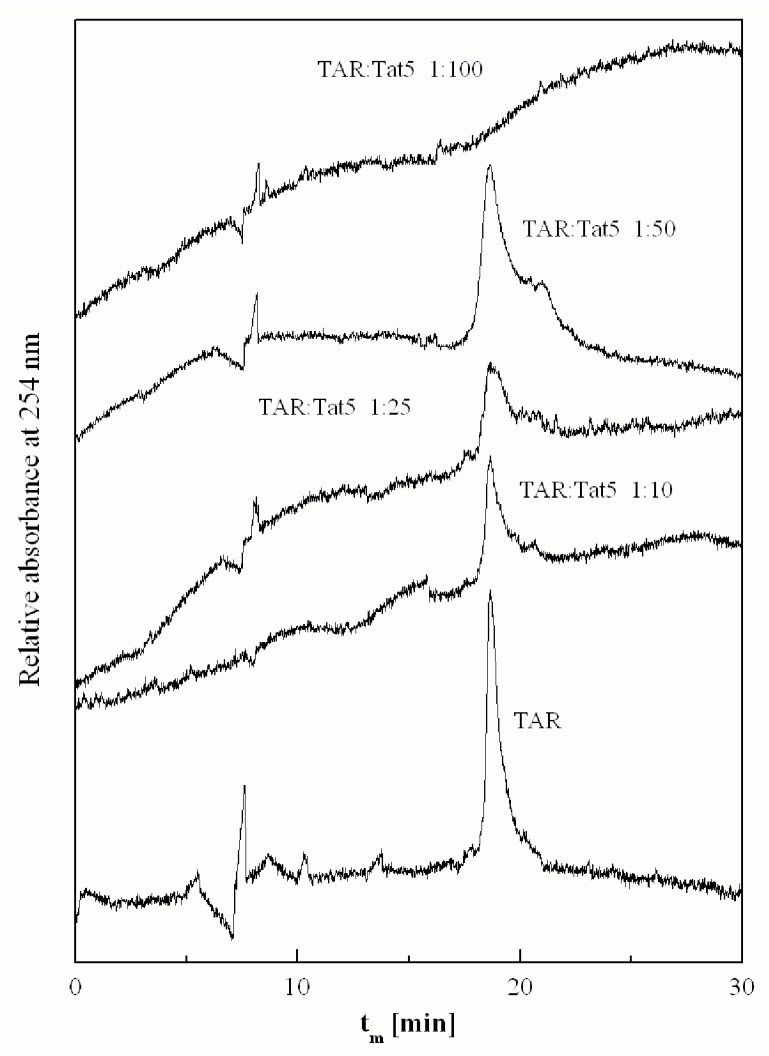

Figure 4. CEMSA of TAR-Tat5 peptide interaction.

The conditions were the same as for Fig. 3. The molar ratio of TAR to Tat5 peptide is shown for each sample analyzed. Peaks with migration time around $7 \mathrm{~min}$ represent buffer effects. duced into the guanidinium group of $\mathrm{Arg}^{52}$ strongly suppressed the peptide binding to TAR (Fig. 4). Only at a high peptides excess, formation of a poorly shaped and broad peak $\left(t_{\mathrm{m}} \approx 21 \mathrm{~min}\right.$ ) was observed. In the presence of a 100-fold excess of Tat5 peptide some turbidity after mixing with TAR was visible and no peaks after sample centrifugation were observed by CEMSA.

\section{DISCUSSION}

The unique advantages of CEMSA for the study of methylation influence on RNA-peptide interaction is demonstrated in the present paper. Key features of CEMSA conditions applied include the use of LPA-coated capillary and soluble sieving matrix in separation buffer. This approach effectively minimized interaction of the macromolecules with the capillary wall. It allowed us to observe well shaped and separated peaks of unbound and bound RNA. Although no quantitative studies have been done, CEMSA showed that the $K_{d}$ values of the RNA-peptide interactions were in the micromolar range. This is in good agreement with previously obtained results (Mucha et al., 2001). CEMSA allowed the monitoring of both positive and negative influence of methylation on RNA-peptide binding. Methylation-dependent binding was observed for the $\mathrm{ASL}^{\mathrm{Phe}}-\mathrm{Cm}_{32}, \mathrm{Gm}_{34}, \mathrm{~m}^{5} \mathrm{C}_{40}$-peptide $\mathrm{t}^{\mathrm{F}} 2$ interaction. The clearly visible complex formation shows the importance of the three methylated nucleosides as the identity elements of the triply modified ASL ${ }^{\text {Phe }}$ when recognized by peptide $\mathrm{t}^{\mathrm{F}} 2$. Using polyacrylamide slab gel electrophoresis (SGE) at similar conditions, we were unsuccessful in monitoring the complex formation.

An opposite effect of methylation was observed for the TAR-Tat peptide system. Asymmetrical dimethylation of the guanidinium group of $\mathrm{Arg}^{52}$ strongly suppressed the TAR-Tat peptide interaction. The result demonstrates that the specific net of hydrogen 
bonds created by the guanidinium group of the conserved $\mathrm{Arg}^{52}$ plays a crucial role in TAR-Tat HIV-1 recognition. The obtained results clearly show that CEMSA may be easily adapted to study the methylation effect on RNA-peptide interaction. This method provides significant improvement in the speed and precision of the study of methylation-dependent interactions of biomolecules. $\mathrm{CE}$ should be generally applicable to studies of the influence of post-transcriptional and posttranslational modifications on interaction of biomolecules.

\section{R E F E R E N C E S}

Agris PF. (1996) The importance of being modified: roles of modified nucleosides and $\mathrm{Mg}^{2+}$ in RNA structure and function. Prog Nucleic Acid Res Mol Biol.; 5: 79-129.

Aletta JM, Cimato TR, Ettinger MJ. (1998) Protein methylation: a signal event in post-translational modification. Trends Biochem Sci.; 23: 89-91.

Ashraf SS, Sochacka E, Cain R, Guenther R, Małkiewicz A, Agris PF. (1999) Single atom modification $(\mathrm{O} \rightarrow \mathrm{S})$ of tRNA confers ribosome binding. RNA.; 5: 188-94.

Auld DS, Schimmel P. (1995) Switching recognition of two tRNA synthetases with an amino acid swap in a designed peptide. Science.; 267: 1994-6.

Calnan BJ, Tidor B, Biancalana S, Hudson D, Frankel AD. (1991) Arginine-mediated RNA recognition: the arginine fork. Science.; 252: 1167-71.

Causse E, Siri N, Arnal JF, Bayle C, Malatray P, Valdiguie P, Salvayre R, Couderc F. (2000) Determination of asymmetrical dimethylarginine by capillary electrophoresis-laser-induced fluorescence. J Chromatogr B Biomed Sci Appl.; 741: 77-83.

Gary JD, Clarke S. (1998) RNA and protein interactions modulated by protein arginine methylation. Prog Nucleic Acid Res Mol Biol.; 61: $66-124$.
Heegaard NH, Kennedy RT. (1999) Identification, quantitation and characterization of biomolecules by capillary electrophoretic analysis of binding interactions. Electrophoresis.; 20: 3122-33.

Helm M, Giege R, Florentz C. (1999) A Watson-Crick base-pair-disrupting methyl group $\left(\mathrm{m}^{1} \mathrm{~A}_{9}\right)$ is sufficient for cloverleaf folding of human mitochondrial tRNA ${ }^{\text {Lys }}$. Biochemistry.; 38: 13338-46.

Karn J. (1999) Tackling Tat. J Mol Biol.; 293: $235-54$.

Liebich HM, Xu G, Di Stefano C, Lehmann R. (1998) Capillary electrophoresis of urinary normal and modified nucleosides of cancer patients. J Chromatogr A.; 793: 341-7.

Lischwe MA, Roberts KD, Yeoman LC, \& Busch H (1982) Nucleolar specific acidic phosphoprotein $\mathrm{C}_{23}$ is highly methylated. $J$ Biol Chem.; 257: 14600-2.

Mucha P, Szyk A, Rekowski P, Weiss PA, Agris PF. (2001) Anticodon domain methylated nucleosides of yeast tRNA(Phe) are significant recognition determinants in the binding of a phage display selected peptide. Biochemistry.; 40: 14191-9.

Mucha P, Szyk A, Rekowski P, Barciszewski J. (2002) Structural requirements for conserved $\mathrm{Arg}^{52}$ residue for interaction of the human immunodeficiency virus type 1 trans-activation responsive element with trans-activator of transcription protein (49-57) Capillary electrophoresis mobility shift assay. J Chromatogr A.; 968: 211-20.

Muramatsu T, Nishikawa K, Nemoto F, Kuchino Y, Nishimura S, Miyazawa T, Yokoyama S. (1988) Codon and amino-acid specificities of a transfer RNA are both converted by a single post-transcriptional modification. Nature.; 336: 179-81.

Putz J, Florentz C, Benseler F, Giege R. (1994) A single methyl group prevents the mischarging of a tRNA. Nat Struct Biol.; 1: $580-2$.

Todorov TI, Morris MD. (2002) Comparison of RNA single-stranded DNA and double-stranded DNA behavior during capillary 
electrophoresis in semidilute polymer solutions. Electrophoresis.; 23: 1033-44.

Yarian C, Marszalek M, Sochacka E, Malkiewicz A, Guenther R, Miskiewicz A, Agris PF. (2000) Modified nucleoside dependent Watson-Crick and wobble codon binding by tRNALys species. Biochemistry.; 39: 13390-5.

Yeung ES. (1999) Study of single cells by using capillary electrophoresis and native fluorescence detection. J Chromatogr A.; 830: 243-62. 